\title{
INFORMATION EXTRACTION OF TOURIST GEOLOGICAL RESOURCES BASED ON 3D VISUALIZATION REMOTE SENSING IMAGE
}

\author{
Wang Xulong \\ Shandong Remote Sensing Center of Technology and Application, Jinan, China -wxllong126@126.com
}

Commission III, WG III/1

KEY WORDS: Remote sensing image, 3D visualization, Tourism geological resources, Information Extraction, Investigation

\begin{abstract}
:
Tourism geological resources are of high value in admiration, scientific research and universal education, which need to be protected and rationally utilized. In the past, most of the remote sensing investigations of tourism geological resources used two-dimensional remote sensing interpretation method, which made it difficult for some geological heritages to be interpreted and led to the omission of some information. This aim of this paper is to assess the value of a method using the three-dimensional visual remote sensing image to extract information of geological heritages. skyline software system is applied to fuse the $0.36 \mathrm{~m}$ aerial images and $5 \mathrm{~m}$ interval DEM to establish the digital earth model. Based on the three-dimensional shape, color tone, shadow, texture and other image features, the distribution of tourism geological resources in Shandong Province and the location of geological heritage sites were obtained, such as geological structure, DaiGu landform, granite landform, Volcanic landform, sandy landform, Waterscapes, etc. The results show that using this method for remote sensing interpretation is highly recognizable, making the interpretation more accurate and comprehensive.
\end{abstract}

\section{INTRODUCTION}

Tourism geological resources are of high value in admiration, scientific research and universal education, which need to be protected and rationally utilized. In the past, most of the remote sensing investigations of tourism geological resources used twodimensional remote sensing interpretation method( $\mathrm{Li}$ et al., 2016; Wang et al., 2017), which made it difficult for some geological heritages to be interpreted and led to the omission of some information. Using the three-dimensional visual remote sensing image to extract tourism geological resources information can effectively improve the accuracy of interpretation and make the extracted information more comprehensive(Hu et al., 2015; Li et al., 2015). The types of tourism geological resources in Shandong Province are diverse and have a high value for tourism development(Wang et al., 2013; Wang et al., 2015). From 2012 to 2017, The remote sensing investigation and evaluation of tourism geological resources was carried out in Shandong Province(Liu et al., 2017). In this paper, taking Shandong Province as an example, the application of this method has been described in detail. This method can not only further broaden the application range of remote sensing technology, but also provide a scientific basis for government to fully grasp the distribution of tourism geological resources and then to find new geoparks and to formulate plans for protection and development.

\section{METHODS}

Firstly, the TM satellite images and $0.36 \mathrm{~m}$ aerial images are geometrically corrected, fused and enhanced. And then, skyline software system is applied to fuse the $0.36 \mathrm{~m}$ aerial images and $5 \mathrm{~m}$ interval DEM to establish the digital earth model. Finally, the background database is built up by superimposing the existing data of basic geology and mineral resources and the basic framework of geographic information, which serves as the basic data for remote sensing interpretation. Based on the threedimensional shape, color tone, shadow, texture and other image features of the geological heritage displayed in the threedimensional visualized remote sensing image, remote sensing interpretation keys are established(Zhao, 2013). According to the interpretation keys, we first use TM satellite images to interpret strata and large geological formations such as fault zones, and then use the three-dimensional high-resolution remote sensing images to observe from different angles and scales to obtain the distribution range of different geological heritage. After that, we carry out field verification to conduct qualitative and quantitative description of geological heritage on site, and to collect coordinate information using GPS equipment, to take photos and videos, and so on. By sorting out all the data, we can make a comprehensive evaluation of the geological heritage to determine the tourism geological resources with the development prospect, and then to establish a database and develop the geographic information system of tourism geological resource.

\section{INFORMATION EXTRACTION}

The categories of geological relics including geological profiles, geological structures, paleontology, minerals and mineral deposits, geomorphologic landscapes, water landscapes, and environmental geological relics, based on "Technical Requirements for Planning and Compiling National Geoparks". It is further divided into 25 types, which are stratum, minerals, rocky landforms, volcanic landforms, waterfall landscapes, et al. In three-dimensional visualization high-resolution remote sensing images, many types of geological relics have features such as visual intuition, high-definition, and rich information. Their performance is relatively unique, and is relatively easy to extract information of geological relics.

\subsection{Geological structure relics}

Among the geological structure relics, many of the faults are piedmont faults, whose linear image features are very obvious. They have a great influence on the geomorphology and turn out 
to be the dividing line between the mountains and the plains. For example, the Wadian Quanyuan Fracture in Jiuxianshan is a piedmont faults(Figure 1). The ring-shaped structure is mainly related to intrusive rock masses and volcanic structures, which is an important reference for finding minerals. The ring-shaped structure caused by diorite rocks in the area of Shanquan Village, Jinan City, whose ring shape is clear and have obvious tonal anomalies on the TM image(Figure 2), the interior of the ring-shaped structure is light pink, and the edge of the ringshaped structure is a hilly hump, with a dark tone outside the ring. The ring-shaped structure in the three-dimensional image is presented as a ring shape with a relatively low center and a raised periphery(Figure 3), this makes it easier to interpret, and where metallic mines usually can be found.

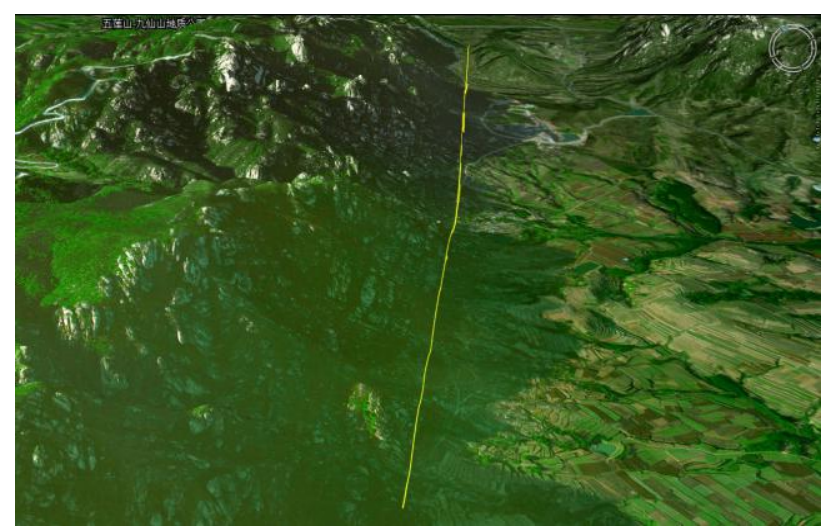

Figure 1. Wadian Quanyuan fracture

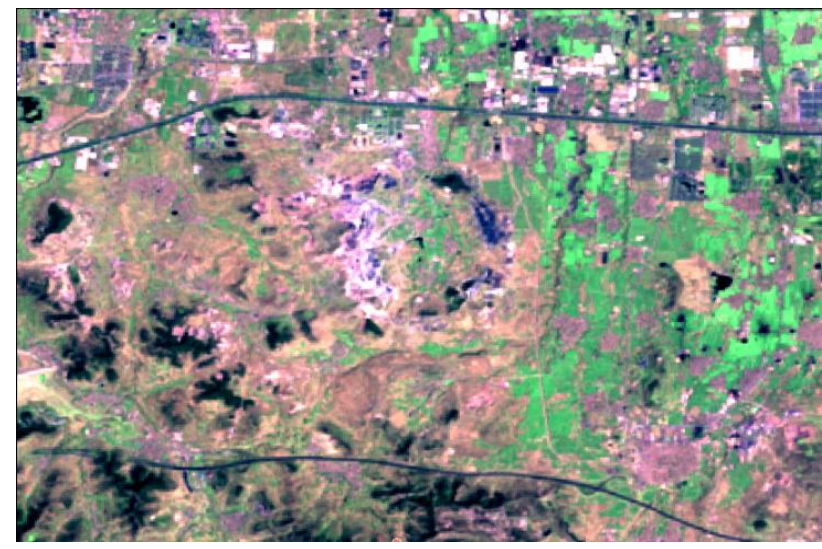

Figure 2. Ring-shaped structure on the TM image

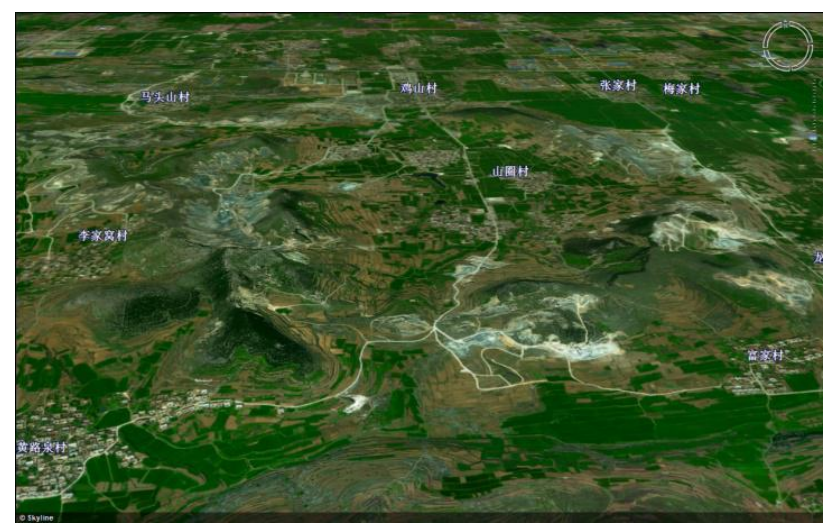

Figure 3. Ring-shaped structure on the 3D image

\subsection{DaiGu landform relics}

The DaiGu landform is mainly formed by the Cambrian limestone. It is a conical shape, but the top of the mountain is relatively flat, surrounded by cliffs, and the slope below the cliff gradually becomes a gentle slope. The image feature of the DaiGu Landform shows as very obvious convex terrain. In the image, it shows pale tonality in the limestone exposure side of the cliff and shadow can be seen in another side, which indicates that there is relative height difference(Figure 4). The exposed limestone and vegetation usually distribute as the shape of concentric circle. Granite also forms a gu-shaped landform, such as the lion $\mathrm{Gu}$ in Yishan, whose shape likes a lion(Figure 5). The lion $\mathrm{Gu}$ is consisted of Late Neoarchean fine-grained monzonite. On the image, the exposed granite is pale yellow, it can be clearly seen that there are many joints in granite, and vegetation does not show concentric rings.

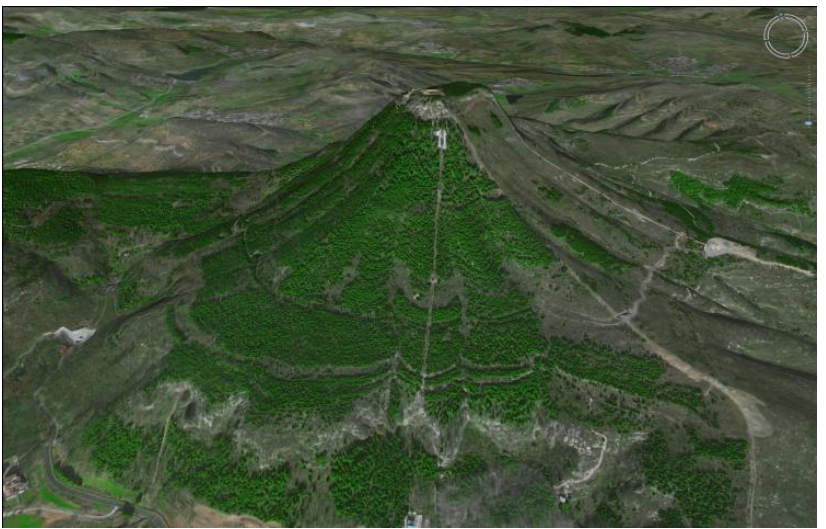

Figure 4. The DaiGu landform: Baodu Gu

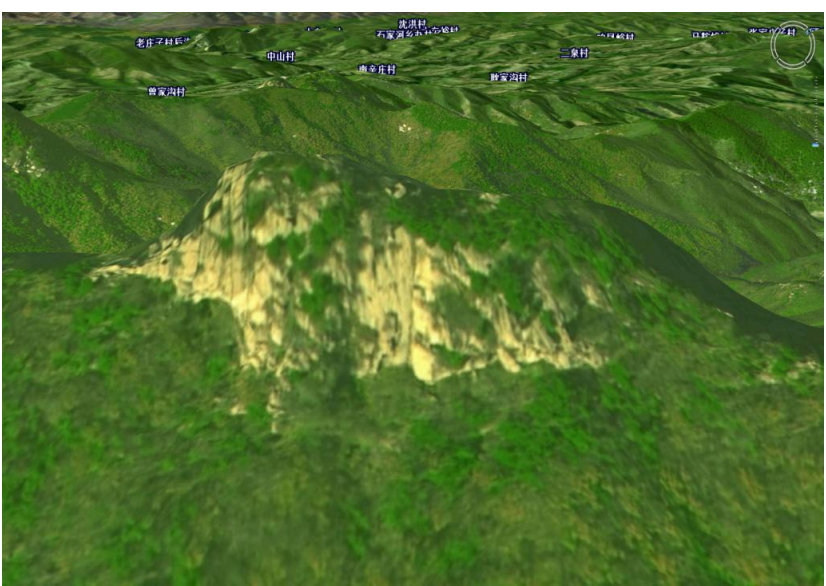

Figure 5. The lion $\mathrm{Gu}$

\subsection{Granite landform relics}

The characteristics of the granite landform mainly depend on the speed of the granite body's rise and erosion after it emerges from the surface, thus resulting in different subtypes. On the image, the granite peak forest landform appears as a boulder rise, the bulge is dense, and the exposed rock is a pale yellow tone(Figure 6). It can be clearly seen that the joint is like a mark which was cut by a knife, the mountain feels more broken. Generally, the joints of granite are relatively developed, and the collapse is relatively strong. This effect will form steep cliffs(Figure 7), at the same time, a large number of megaliths fell from the mountain and filled the valley to form a stone waterfall, such as the formation of dozens of stone waterfall in 
Laoshan(Figure 8). The cause of the stone sea in Yishan is a similar like this. Due to the spherical weathering effect, a spectacular stone egg landform is formed on the Yishan, which can be visually seen on the image. The landscape of the canyon landform appears curved in a three-dimensional visualization image(Figure 9), the exposed granite is bright yellow, the river is dark blue and the vegetation coverage is high.

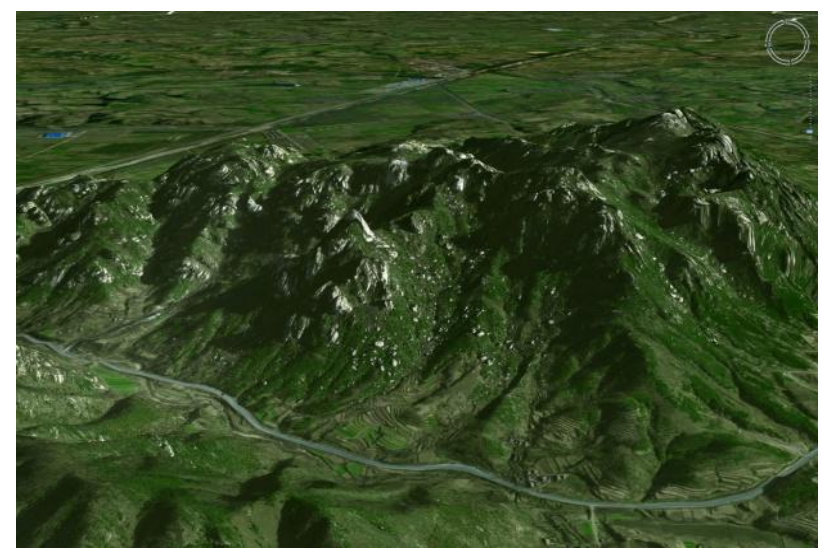

Figure 6. Wulianshan peak forest landform

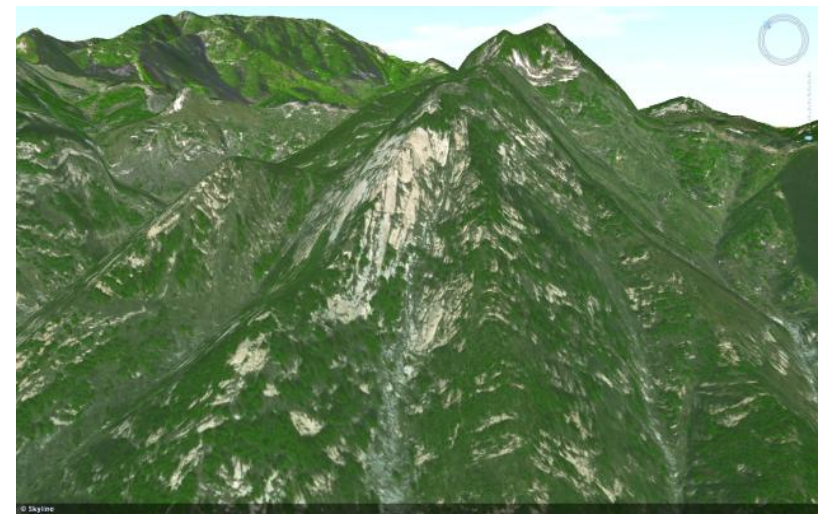

Figure 7. Steep cliffs and joints of Taishan

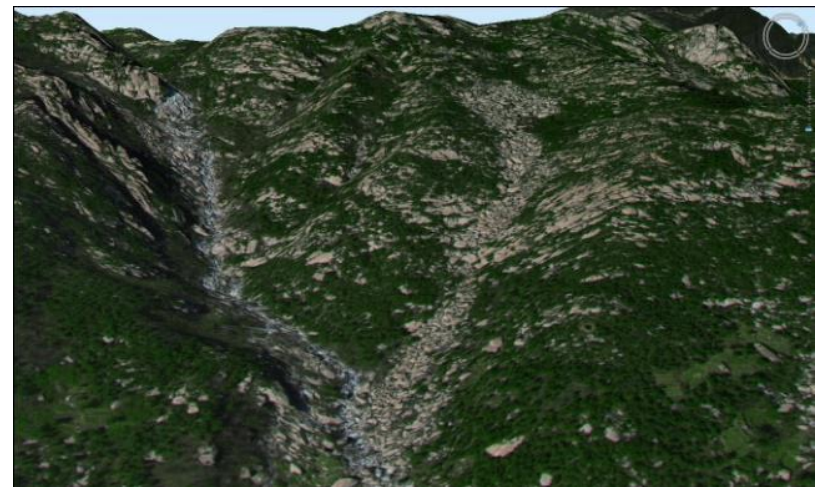

Figure 8. Laoshan stone waterfall

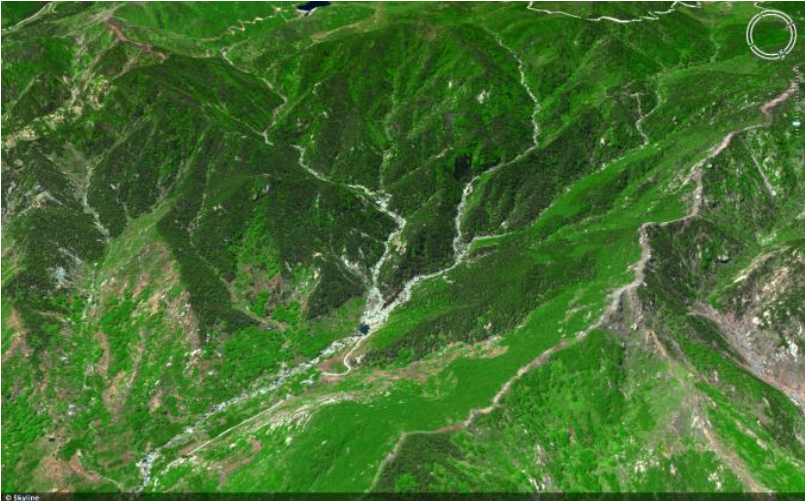

Figure 9. Longwan canyon landform

\subsection{Volcanic landform relics}

Volcanic landforms mainly include volcanic lava, craters and volcanic cones, et al. In the high resolution remote sensing image, the exposed basalt is dark brown, such as Tiejueshan and Jieshishan, the surface of the mountain formed by volcanic clastic rock is not smooth. The particles formed on the image of the rock feel rough, the crater has a strong concave-convex shape, showing a round or semicircular shape, and the vegetation coverage is better. The Yintaishan volcanic cone appears as a raised boulder on the three-dimensional visualization image, with no vegetation cover, and it contrasts sharply with the surrounding environment. According to this, the mountaintop in the western part of Yintaishan was also interpreted as a crater(Figure 10). The Chamashan is an ancient pyroclastic cone with a conical shape(Figure 11). The slope of the lower part of the volcanic cone is small and the upper part is large. the top is flat and concave, it is a caldera. Yaoshan is a shield volcano(Figure 12), the slope of the hill is small, ranging from 5 degrees to 10 degrees. It is a lava cone. The volcano is surrounded by volcanic clastic rock, which is easily eroded by flowing water and generates radial gully.

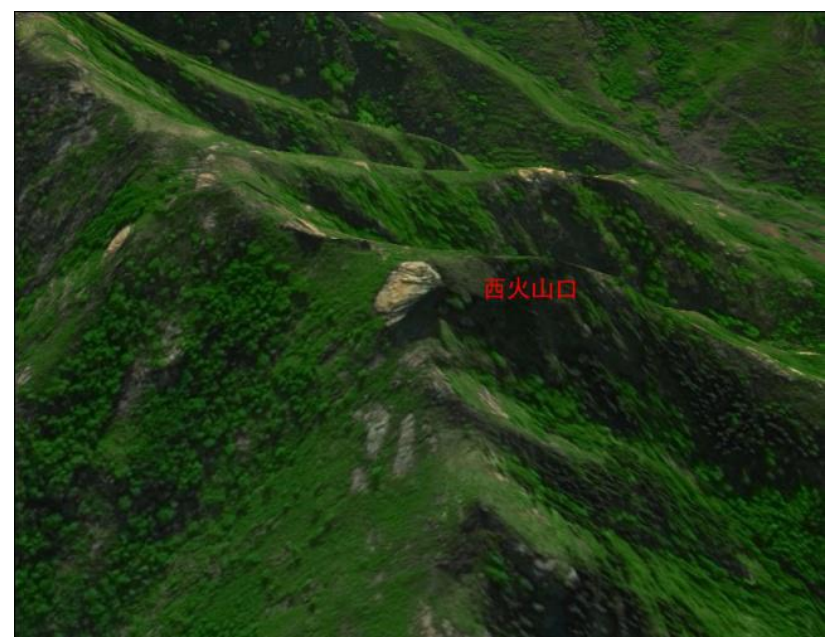

Figure 10. The crater in the western part of Yintaishan 


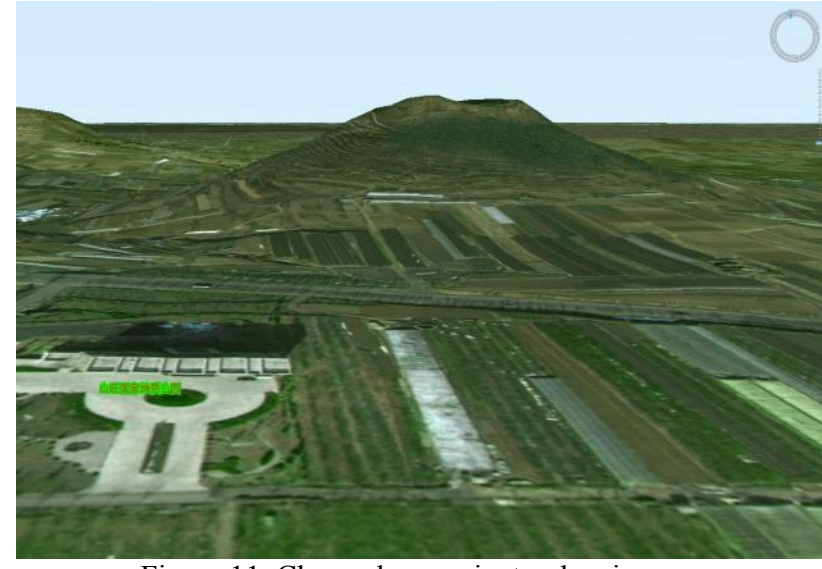

Figure 11. Chamashan ancient volcanic cone

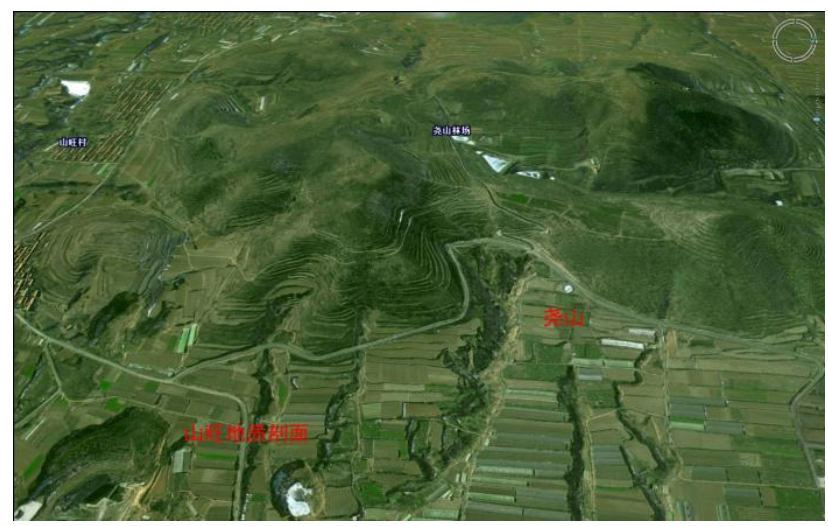

Figure 12. Yaoshan shield volcano

\subsection{Sandy landform relics}

There are a lot of silt left in the old course of the Yellow River in Linqing. Under the action of wind, various sand dunes and sand ridges are formed. This is the typical sandy landform landscape in Shandong province(Figure 13). Various sand dunes and sand ridges are small convex on remote sensing images, which are shaded and have a pale yellow hue, and are brighter than the dark yellow hue of surrounding farmland. In most cases, the tree coverage is high.

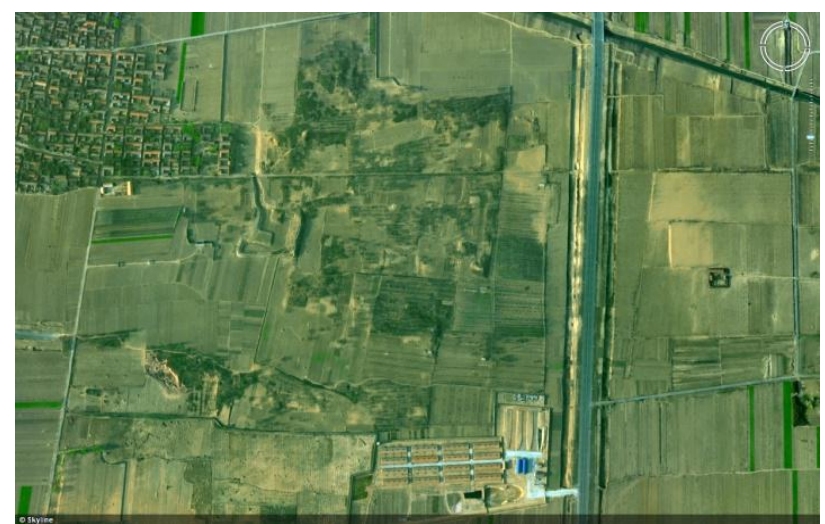

Figure 13. The old course of the Yellow River in Linqing

\subsection{Sea erosion and marine accumulation landform relics}

Shandong Province has a long coastline, and there are many sea erosion and marine accumulation landform(Figure 14). Sea cliffs appear as steep cliffs on the seashore in three-dimensional visualization images, and the height difference is obvious.
Affected by the erosion of seawater, the upper part of some sea cliffs stretch out from the coast and forms shadows. The marine accumulation landforms are mainly formed by the accumulation of gravels. In the high-resolution images, we can see that the megaliths are distributed in strips or connected to a line.

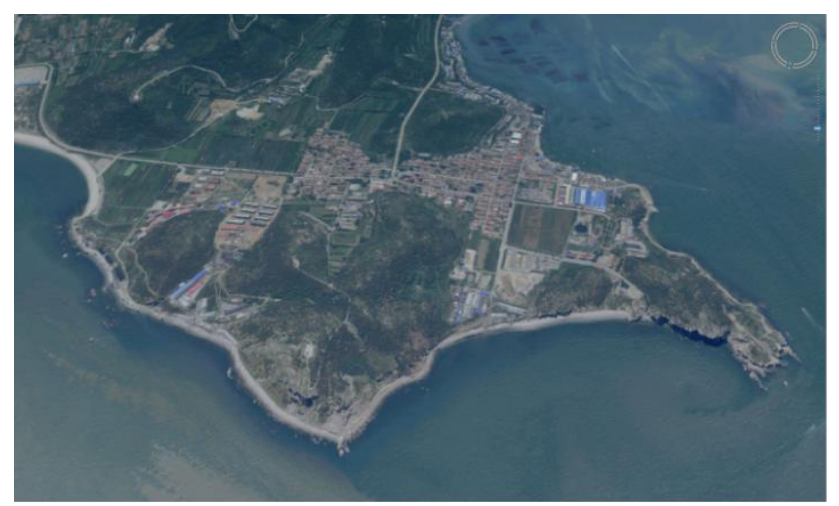

Figure 14. Sea erosion and marine accumulation landform

\subsection{Waterscapes relics}

Waterscapes such as springs, lakes and river reaches are usually dark blue on the images, The surface of them is relatively smooth, and the surrounding vegetation has a high coverage and it is easy to interpret. Extracting waterfall information from two-dimensional images is difficult, and it become easier by use three-dimensional methods. The waterfalls are generally distributed on steep cliffs. Usually, there are rivers above waterfalls, and the water is constantly flowing, and falls suddenly from steep cliffs to form waterfalls. All these features can be intuitively displayed on the three-dimensional visualization images, such as Juyushan falls(Figure 15). The color of the waterfall on the image is bright black or light blue.

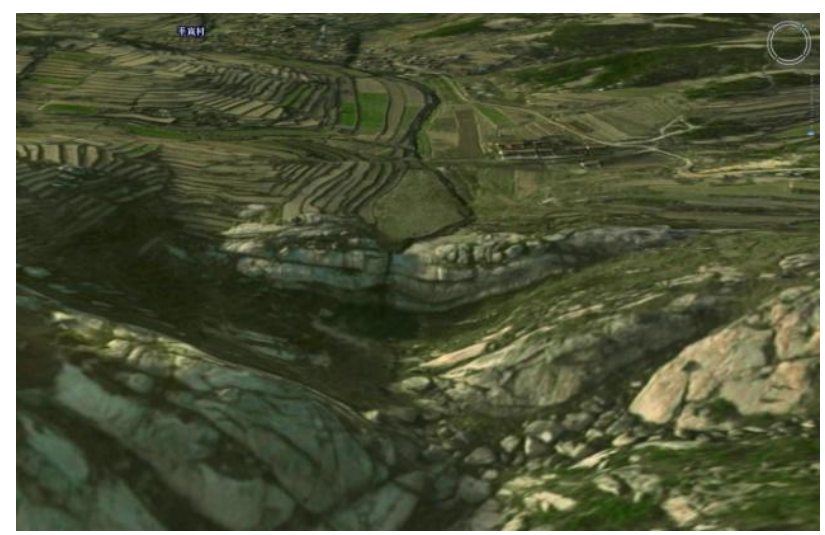

Figure 15. Juyushan falls

\subsection{Negative topography relics}

Other geological relics that can also be interpreted from $3 \mathrm{D}$ visualization remote sensing images including negative topography, such as pits, crater basins(Figure 16), et al. Mining landscapes are easily found using the negative terrain threedimensional features of the pit. The type of negative karst landform is represented by the Yangtian Trough on the Yangtianshan in Qingzhou(Figure 17). The Yangtian Trough is located on the top of the mountain, the top is a platform which elevation is from $750 \mathrm{~m}$ to $840 \mathrm{~m}$. The edge of the platform is relatively high and the inside is a low-lying land. The bottom of the low-lying land is a long strip of flat land. In the image, it is shaped like a horse's trough. 


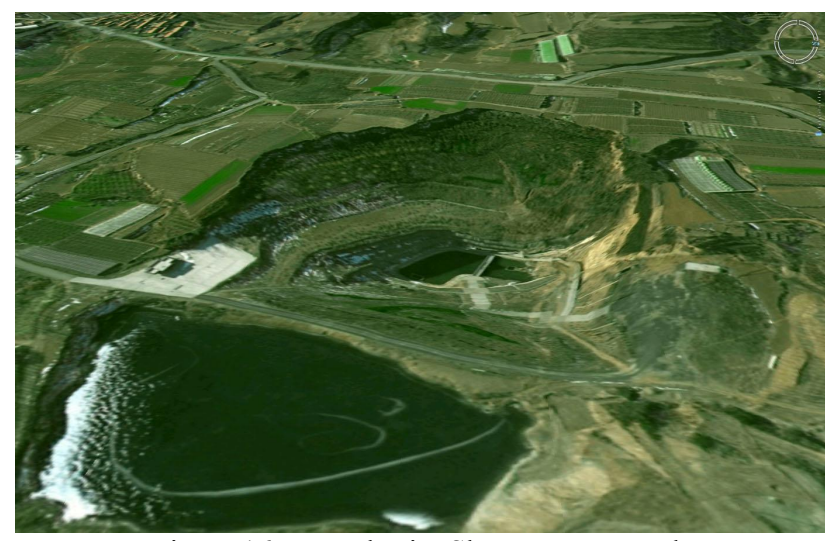

Figure 16. crater basin Shanwang geopark

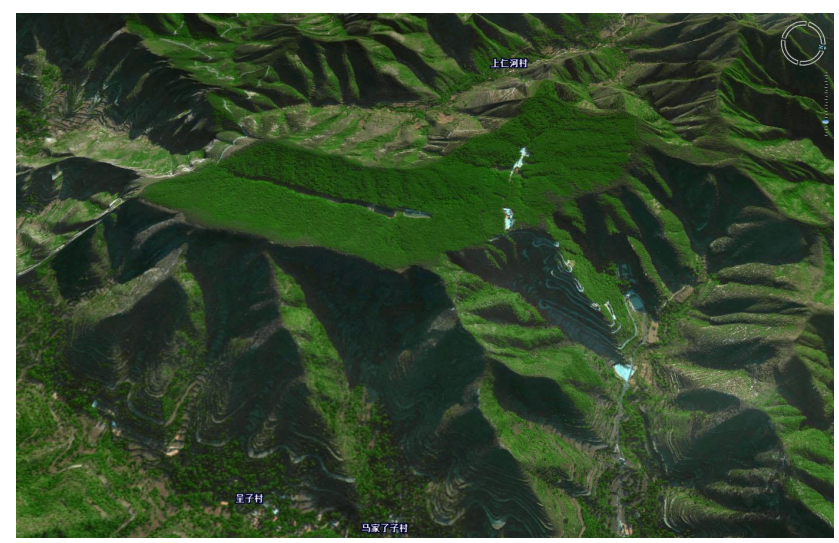

Figure 17. The Yangtian Trough

\subsection{Earthquake relics}

The geological collapse of Xiong'ershan is a typical earthquake relic. The Xiong'ershan is very steep, with many cracks and the rocks are broken. There is a difference in the lithological composition of the cliffs. The upper part of the cliff is hard and the lower part is soft. It is the place where the collapse is most likely to occur. The geological collapse occurred due to the affect of earthquake. As we can see from the image, square megaliths are piled up at the foot of the mountain. The faults and earthquake remnants of the Maipo Park in Malingshan have two tones on the three-dimensional visualization image, and the linear features are obvious.

\subsection{Geological disasters relics}

Relics of geological disasters mainly include mountain remnants, landslides, and debris flow(Luo et al., 2010), using three-dimensional information, interpretation is relatively easy.

\section{RESULTS}

Through remote sensing interpretation and field investigation, the distribution of tourism geological resources in Shandong Province and the location of geological heritage were obtained. Information of 917 geological heritage sites was obtained. At the same time, 127 geoheritage concentration region were interpreted, including typical geological sections, fossils of paleontology, Geological-geomorphologic landscapes and water landscapes. There were 64 geoparks in the work area, all of them were delineated. Through the comprehensive evaluation of resources, A number of geological heritages with development value were selected, including granite landforms such as
Laoshan in Qingdao, Dazhushan- Lingshan Island and Xiaozhushan in Huangdao District, Dazeshan in Pingdu, Cambrian Geological Landscape in Jiulongshan in Laiwu, volcanic landform such as Yintaishan in Zouping, Tiejueshan in Huangdao. Several geological heritages with conservation significance have been determined, including the Cambrian Limestone in the Guli town of Xintai and Yong'an Township of Zaozhuang, the Yan Ling Guan group pillow-shaped basalt in Yanlingguan village of Tai'an, the old course of the Yellow River in Xiajin, the ring-shaped structure in Shanquan village of Jinan, the pillow-shaped basalt in seven stars typhoon scenic area. In accordance with a uniform standard, we used the results of interpretation, photos, videos and other information of geological heritage to establish a database. We used the threedimensional GIS technology to develop the three-dimensional geographic information system of tourism geological resources in Shandong Province(Wang, 2012). The system realize the multi-functional integrated management and application of tourism geological resources. This provides a solid and reliable reference for the protection and development of tourism geological resources and scientific research in the work area.

\section{CONCLUSION}

The results show that TM satellite images have advantages in interpreting large geological structures. The three-dimensional visualization remote sensing image has the advantages of threedimensional shape, high definition and fine texture, and can comprehensively observe the geological heritage and related topography, and can well interpret the geological heritage such as piedmont faults, DaiGu landform, volcanic structure, geological collapse, ring-shaped structure, peak forest landform, granite joints, stone waterfalls, negative terrain, waterfalls, earthquake relics, debris flow, landslides and others. Using this method for remote sensing interpretation is highly recognizable, making the interpretation more accurate and comprehensive. Due to the influence of vegetation cover and resolution of images, it is relatively difficult to interpret some other geological heritages and must be complemented by geological data and other research methods such as field surveys.

\section{APPENDIX (OPTIONAL)}

Authors would like to thank Research Professor Liu Qizhi, Research Professor Zhao Yumei, and Research Professor Wang Shijin, and "Remote Sensing Investigation and Evaluation of Tourism Geological Resources in Shandong Province" project team.

\section{REFERENCES}

Hu C Z., Tian Q J., 2015. Analysis of Longpan-Qiaohou Fault Geometric Structure by Using 3-D Visualization of Satellite Remote Sensing Image. Technology for Earthquake Disaster Prevention, 10(4), pp. 819-830.

Li P J., Qiu J T., 2016. Application of Remote Sensing in Investigation and Assessment of Geoparks and GeoheritagesTaking Southern Sichuan for Instance. Resource Development \& Market, 32( 5), pp. 513-517.

Liu Q Z., Wang X L., 2017. Remote sensing investigation and evaluation of tourism geological resources in Shandong Province. Shandong Map Press, Jinan, pp. 1-15. 
The International Archives of the Photogrammetry, Remote Sensing and Spatial Information Sciences, Volume XLII-3, 2018 ISPRS TC III Mid-term Symposium "Developments, Technologies and Applications in Remote Sensing", 7-10 May, Beijing, China

Li Y., Zhu J N., 2015. Application of 3D visualization of remote sensing images in regional geological survey in the west Kunlun Mountains, Xinjiang. Journal of Geology, 39(3), pp. $451-455$

Luo Z F., Qi X., 2010. Application of Three-Dimensional Visualization of Remote Sensing Images in the Investigation of the Nangou Debris Flow. Environmental Science and management, 35(1), pp. 143-146.

Wang S J., Wan Y S., 2015. Characteristics of major geological heritages of the geoparks in Shandong Province. Acta Geoscientica Sinica, 36(5), pp. 669-684.

Wang S J., Wan Y S., Zhang Z Q., 2013. Forming age and distribution characteristics of major types of geological heritage in Shandong Province. Shandong Land And Resources, 29(2), pp. 1-12.

Wang X L., 2012. Study on the Framework of 3D Remote Sensing Information System Sharing Platform for Digital Land in Shandong Province. Bulletin of Surveying and Mapping, S1, pp.417-420.

Wang Y L., Dong W H., 2017. Application of ZY-1 02C remote sensing data to the investigation of geoparks: Taking tixian County, Tianjin city for example. Remote Sensing for Land and Resources, 29(s1), pp.95-100.

Zhao Y S., 2013. Analysis principle and method of remote sensing applications. Science Press, Beijing, pp. 483-490. 